\title{
EFFECT OF PHYTIC ACID (IP6) VERSUS ETHYLENE DIAMINE TETRA ACETIC ACID (EDTA) ON DENTIN MICROHARDNESS (IN VITRO STUDY)
}

\author{
Mohamed M. Naeem ${ }^{1 *} B D S$, Amr M. Abdallah² $P h D$, Adel A. Kamar ${ }^{3} P h D$, Nihal A. Leheta ${ }^{4} P h D$.
}

\begin{abstract}
INTRODUCTION: The use of chelating agents removes smear layer, increasing the access of irrigants to allow disinfection, and also reduces microhardness. Microhardness is an indirect evidence of mineral changes in dentin. Its reduction facilitates the instrumentation throughout the canal but, it may weaken the root and increases permeability of dentin. Therefore, finding a biocompatible chelating agent with better chelating ability is mandatory.

OBJECTIVE: To evaluate the effect Phytic acid (IP6) with different concentrations and ethylene diamine tetra-acetic acid (EDTA) solution on microhardness of radicular dentin.

MATERIALS AND METHOD: This study was conducted on 30 single rooted permanent maxillary anteriors. Teeth were instrumented using rotary files and irrigated in between using $2 \mathrm{ml} 2.5 \% \mathrm{NaOCl}$, then were sectioned longitudinally into halves giving 60 specimens that were embedded in acrylic resin leaving the dentin exposed. After polishing, the microhardness values of the untreated dentin were recorded by Vicker's microhardness tester. The root halves were divided into 4 groups composed of 15 samples each and immersed for 5 minutes with one of the chelating solutions, Group I: Immersed in $10 \mathrm{ml}$ of (IP6) $0.5 \%$ followed by $10 \mathrm{ml}$ of $2.5 \%$ (NaOCl), Group II: Immersed in $10 \mathrm{ml}$ of (IP6) $1 \%$ followed by $10 \mathrm{ml}$ of $2.5 \% \mathrm{NaOCl}$, Group III: Immersed in $10 \mathrm{ml}$ of $1.5 \%$ (IP6) followed by $10 \mathrm{ml}$ of $2.5 \% \mathrm{NaOCl}$, Group IV: Immersed in $10 \mathrm{ml}$ of $17 \%$ EDTA solution followed by $10 \mathrm{ml}$ of $2.5 \% \mathrm{NaOCl}$. Then microhardness values were recorded, and calculation of the difference between baseline values and post-application values were calculated.

RESULTS: Tested chelators reduced microhardness of the dentin. $17 \%$ EDTA reduced the microhardness more significantly than $0.5 \%, 1 \%$ and $1.5 \%$ IP6.
\end{abstract}

CONCLUSION: Using IP6 with different concentrations had less detrimental effect on dentin microhardness than EDTA.

KEY WORDS: Phytic acid, EDTA, smear layer, dentin microhardness.

RUNNING TITLE: Dentin microhardness after different chelating solutions application.

1 Bachelor of Dentistry, Conservative Dentistry Department, Faculty of Dentistry, Alexandria University, Alexandria, Egypt

2 Professor of Endodontics, Conservative Dentistry Department, Faculty of Dentistry, Alexandria University, Alexandria, Egypt.

3 Professor of Dental Biomaterials, Dental Biomaterials Department, Faculty of Dentistry, Alexandria University, Alexandria, Egypt.

4 Lecturer of Endodontics Conservative Dentistry Department, Faculty of Dentistry, Alexandria University, Alexandria, Egypt.

* Corresponding Author:

E-mail: Mohamedmagdyyy90@gmail.com

\section{INTRODUCTION}

The success of root canal treatment depends on the quality of instrumentation, irrigation, disinfection, and three-dimensional obturation of the root canal. Endodontic instrumentation using either manual or rotary systems, produces a smear layer and plugs of inorganic particles of calcified tissue and organic components such as pulp tissue debris, odontoblastic processes, microorganisms, and blood cells in dentinal tubules (1).

Therefore removal of the smear layer before obturation is highly recommended. Using sodium hypochlorite $(\mathrm{NaOCl})$ in concentration ranging from $0.5 \%$ to $5.25 \%$ solely cannot effectively remove the smear layer. Ethylene diamine tetra acetic acid (EDTA PH 7.7) has been the most commonly used irrigant for this purpose in a concentration of $17 \%$ from one to five minutes as it is generally accepted as the most effective chelating agent in endodontic therapy (2).

The use of chelating agents during biomechanical preparation of root canals removes smear layer, increasing the access of the irrigant into the dentin tubules to allow adequate disinfection, reducing dentin microhardness, facilitating the access and action of endodontic instruments. Chelating agents decalcify the dentin by combining with the calcium ions of the tooth structure. The decalcifying effect of chelating agents depends largely on application time, solution $\mathrm{pH}$, and concentrations (3).

EDTA is most commonly synthesized on an industrial scale from ethylenediamine, formaldehyde, and sodium cyanide. This synthetic persistent material is being overused and is considered one of the major organic pollutants discharged in water. Bearing in mind that EDTA is not readily biodegradable, there have been some concerns about the leakage of this irrigant into the periapical tissue. Because of these concerns, the extrusion of EDTA beyond the root canal should be avoided (4). Considering these facts, an alternative agent for smear layer removal is necessary, and the search for more biocompatible materials to replace EDTA is still going on.

Phytic acid (Inositolhexakisphosphate (IP6) PH 1.3), a 
promising novel chelating agent is now being tested as a reputable competitive to the EDTA whereas IP6 is a natural organic product that has been proven to be a biocompatible material to periapical tissues and an effective smear layer removal agent (5).

Ip6 is the major storage form of phosphorus in plant seeds and brans that contributes to a variety of cellular functions. IP6 can be extracted with low cost from rice brans. This agent has multiple negative charges, making it an effective chelator of multivalent cations such as calcium $(\mathrm{Ca}+2)$, magnesium, and iron.

Chelating solutions may induce adverse changes in physical properties of dentin, including the microhardness. Although a reduction in microhardness eases the instrumentation throughout the root canal treatment, it may also weaken the root structure. Microhardness determination can provide indirect evidence for losing or gaining any mineral substance in the dental hard tissues. Alteration of surface microhardness of dental hard tissues treated with tested chelating agents could be evaluated using Vicker's microhardness tester or knoop microhardness tester.

The aim of this study was to assess the effect of using phytic acid with different concentrations versus 17\% EDTA solutions on human radicular dentin microhardness. The null hypothesis of this study was that phytic acid with different concentrations and EDTA would have the same effect on dentin microhardness.

\section{MATERIALS AND METHODS \\ Preparation of teeth specimens}

After the acceptance of ethics committee in faculty of dentistry Alexandria university, thirty sound maxillary anterior teeth with closed apices indicated for extraction for periodontal reason were collected from adult patients and were used in this study. Teeth with previous root caries, fractures, curved canals, endodontic treatment, internal resorption or calcification were excluded. The teeth were thoroughly cleaned from any soft tissue or calculus deposition then they were stored in isotonic saline solution at room temperature till time of use. All the teeth were radiographed in the proximal and labial views to confirm presence of a patent single canal.

The crowns of all specimens were decoronated transversally at the cemento-enamel junction (CEJ) with a double-faced diamond disc (Microdont LDA. Brazil) at low speed, with water coolant, to ensure a uniform sample length of $15 \mathrm{~mm} \pm$ $1 \mathrm{~mm}$ root length.

Canal preparation: All teeth were instrumented by introducing $\quad$ Size $15 \quad$ K-File (Mani, Inc, Japan) inside the root canal until it just exited the apical foramen then the file was retracted to be flushed with the apex. One millimeter was subtracted from this length and was taken as the final working length (WL). All teeth were instrumented to the full WL using stainless steel K-Files to a size \#20 followed by the ProTaper Next (Dentsply Maillefer, Ballaigues, Switzerland) rotary system up to size X4 (size 40,.06 taper). Following the use of each sequential file, they were cleaned with sterile gauze and apical patency was checked with K-file size \# 10. Canals in all groups were irrigated with a standardized volume of two $\mathrm{ml}$ of $2,5 \%$ $\mathrm{NaOCl}$ using a universal 27-gauge needle between each file (6).
Specimen preparation for microhardness evaluation: Teeth were longitudinally sectioned in a buccolingual direction by making a thin slot along the buccal and lingual aspects of the root using a double faced diamond disk at low speed (Microdont LDA. Brazil), without passing through the canal space. This was followed by using a chisel and mallet to split the root, then the specimens were prepared for microhardness test evaluation $(3,7)$. Sixty root segments were horizontally embedded in autopolymerizing acrylic resin (ACROSTONE, Dent Product. Egypt) leaving their dentin surface exposed. The dentin surface of the mounted specimens was ground flat and smooth with a series of ascending grades of carbide abrasive papers 500, 800, 1,000, and 1, 200 grit (BIGO, Dent Product. Germany) under distilled water to remove any surface scratches and finally polished with $0.1-1 \mathrm{~mm}$ alumina suspension on a rotary felt disc (MICRODONT LDA. Brazil) to obtain a smooth glossy mirror-like surface.

Measurement of dentin microhardness: Microhardness was measured for each specimen at baseline and after application of different chelating solution. Baseline microhardness value was measured using Vickers Microhardness Tester (Model 402 MVD, ITW Test \& Measurement, Shanghai Co., Ltd) at magnification of x100 using a $25 \mathrm{gm}$ load for 10 seconds. The microhardness measurements were taken either on the buccal or lingual side and were determined at three different points for each sectioned root: on the coronal, middle and apical thirds. Each sectioned root was equally divided into three thirds representing coronal, middle and apical third. In each third (corono-apically), two centrally located points were determined, the first point of measurement represents the baseline value while the second point of measurement represents the post application value after immersion in the tested chelating agent such that the distance between the two points was at least $1 \mathrm{~mm}$, the indentation was made on the dentin surface approximately at $200 \mu \mathrm{m}$ from the canal-dentin interface for standardization $(6,8)$ as shown in figure (1A, $1 \mathrm{~B})$. The Vickers hardness value is obtained by dividing the test force by the area of the sloping faces of the indentation. The resulting impression of the two diagonals was observed with an optical microscope and the average length of the two diagonals was measured by the built-in scaled micrometer and converted into Vickers hardness number (VHN) as shown in figure (1C, 1D) with the following equation: $\mathrm{HV}=1854(\mathrm{~F} / \mathrm{D} 2)$ $(6,9)$.

The constant value of the equation was calculated from the specific geometry of the indenter, $\mathrm{F}$ being the applied load in gram force and $\mathrm{D}$ being the diagonals of the indentation in $(\mu \mathrm{m})$.

Evaluation of microhardness for the tested irrigants: The specimens were randomly divided into 4 groups $(n=15)$ according to the solution used. Then each sample was immersed in each tested chelating solution as follows:

Group I: 15 specimens were immersed in $10 \mathrm{ml}$ of 0.5\%IP6(Sigma-Aldrich Corporation, USA.) and left for 5 minutes then were removed and immersed in $10 \mathrm{ml}$ of $2.5 \%$ NaOCL (Dexa, Health tech. company, A.R.E) for 5 minutes.

Group II: 15 specimens were immersed in 10ml 1\% IP6 and left for 5 minutes then were removed and immersed in $10 \mathrm{ml}$ of $2.5 \% \mathrm{NaOCl}$ for 5 minutes.

Group III: 15 specimens were immersed in 10ml of 1.5\% IP6 
and left for 5minutes then were removed and immersed in

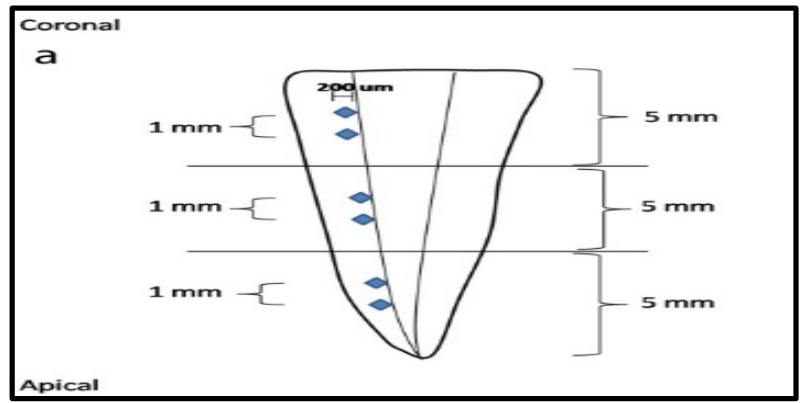

(A)

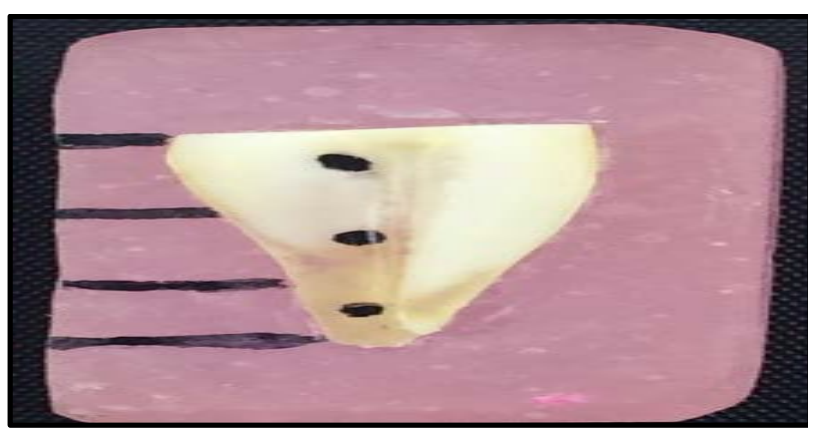

(B)

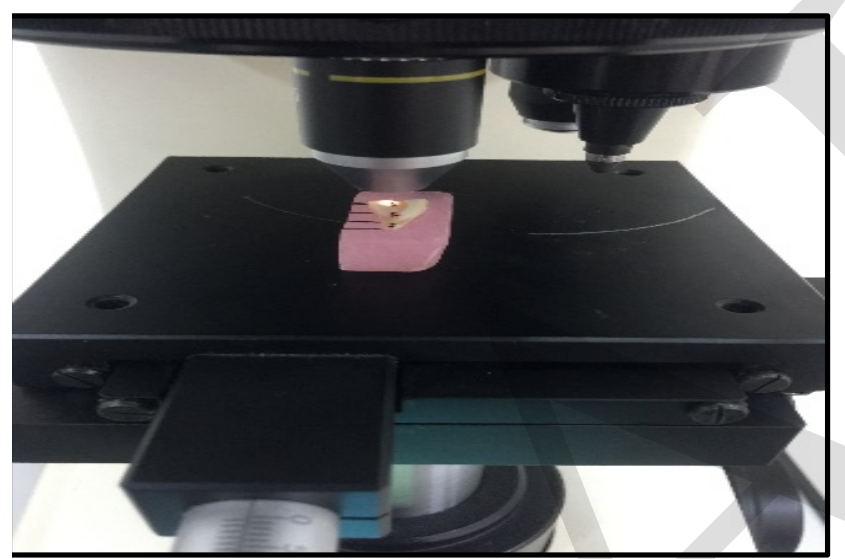

(C)

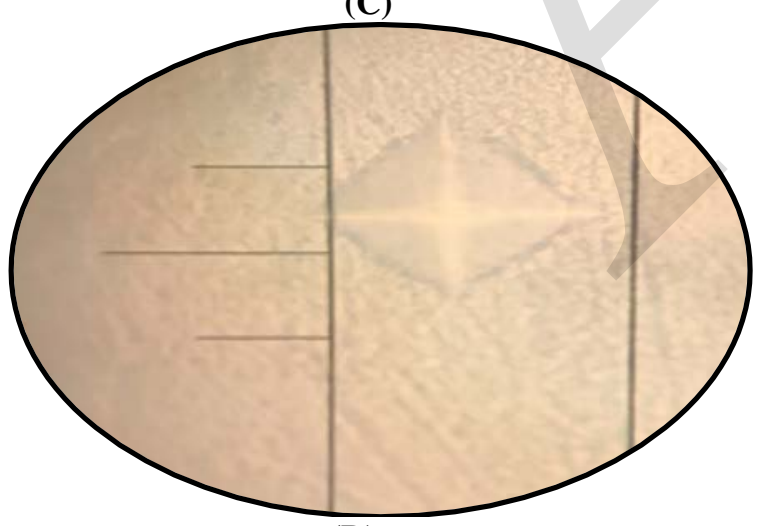

(D)

Figure (1): Showing

(A)Diagram showing the first and second point measurement location.

(B) The analogue image of the diagram.

(C) Mounting the specimen for measurement.

(D)Analogue image (photomicrograph) of the square based pyramid shaped of the impression of the diamond

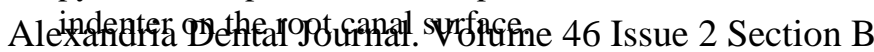

$10 \mathrm{ml}$ of $2.5 \%$ NaOCL for 5 minutes.

Group IV: 15 specimens were immersed in $10 \mathrm{ml}$ of $17 \%$ EDTA (Dharma Research, Inc. USA.) And left for 5minutes then were removed and immersed in $10 \mathrm{ml}$ of $2.5 \% \mathrm{NaOCL}$ for 5 minutes.

After immersion all experimental specimens were dried by gentle air spray. The microhardness was measured for canal dentin surface in close proximity to the initial indentation areas to record the post-treatment VHN.

The percent change in microhardness was calculated as the difference between baseline values and post application values after immersion in the tested irrigants; as shown in the following equation $(10,11)$ :

$$
\frac{|\mathrm{V} 1-\mathrm{V} 2|}{\mathrm{V} 1 \times 100}
$$

$(\mathrm{V} 1$ = Preoperative VHN, V2 = Postoperative VHN)

\section{Statistical analysis of the data}

Data were fed to the computer and analyzed using IBM SPSS software package version 20.0. (Armonk, NY: IBM Corp). The Kolmogorov-Smirnov test was used to verify the normality of distribution Quantitative data were described using range (minimum and maximum), mean, standard deviation and median. Significance of the obtained results was judged at the $5 \%$ level.

The used tests were Student t-test for normally distributed quantitative variables, to compare between two studied groups , F-test (ANOVA)for normally distributed quantitative variables, to compare between more than two groups, and Post Hoc test (Tukey) for pairwise comparisons, Paired t-test for normally distributed quantitative variables, to compare between two periods, and Kruskal Wallis test for abnormally distributed quantitative variables, to compare between more than two studied groups, and Post Hoc (Dunn's multiple comparisons test) for pairwise comparisons.

\section{RESULTS}

There were no statistically significant differences between the mean of pre-treatment Vickers's hardness number (VHN) values for all tested groups, while after immersion of the specimens in the chelating solutions for 5 minutes, all chelating solutions significantly decreased the microhardness of the canal dentin surface compared to the pre-treatment values ( $\mathrm{P}$ value for group I is 0.014 , group II is 0.001 , group III is $<0.001$ and group IV is $<0.001$ ) .

Group IV (EDTA 17\%) showed the highest percentage decrease in microhardness values and was equal to $24.92 \pm 15.93$ (VHN), followed by group III (IP6 1.5\%) where the percentage decrease was equal to $8.27 \pm 3.72$ (VHN), then group II (IP6 1\%) where the percentage decrease was equal to $8.45 \pm 5.66$ (VHN). The lowest percentage decrease was found in group I (IP6 0.5\%) and the percentage decrease was equal to $5.64 \pm 8.16$ (VHN). There was no significant difference between group I, group II and group III when compared to each other, while a significant difference was found when comparing each of these 3 groups with the EDTA group(GpIV) as shown in table (1), figure (2).

It was found that there was no significant difference between the coronal, middle and apical thirds regarding the percentage decrease values in each group as shown in table (2) and figure (3). 
Table (1): Comparison between the four studied groups according to the percentage decrease values of the means of the three zones of the different studied groups.

\begin{tabular}{|c|c|c|c|c|c|c|}
\hline Average & $\begin{array}{l}\text { Group I } \\
(\mathrm{n}=15)\end{array}$ & $\begin{array}{c}\text { Group } \\
\text { II } \\
(\mathbf{n}=15)\end{array}$ & $\begin{array}{c}\text { Group } \\
\text { III } \\
(\mathbf{n}=\mathbf{1 5})\end{array}$ & $\begin{array}{c}\text { Group } \\
\text { IV } \\
(\mathbf{n}=15)\end{array}$ & H & $\mathbf{p}$ \\
\hline$\%$ Change & & & & & & \\
\hline Min. - & $-8.58-$ & $-0.79-$ & $2.22-$ & $1.39-$ & & \\
\hline Max. & 21.33 & 23.59 & 18.71 & 49.68 & & \\
\hline Mean \pm & $5.64 \pm$ & $8.45 \pm$ & $8.27 \pm$ & $24.92 \pm$ & $13.636^{*}$ & $0.003^{*}$ \\
\hline SD. & 8.16 & 5.66 & 3.72 & 15.93 & & \\
\hline Median & 2.97 & 6.92 & 7.57 & 25.61 & & \\
\hline $\begin{array}{l}\text { Sig. bet. } \\
\text { grps }\end{array}$ & \multicolumn{4}{|c|}{$\begin{array}{c}\mathrm{p}_{1}=0.326, \mathrm{p}_{2}=0.191, \mathrm{p}_{3}<0.001^{*}, \mathrm{p}_{4}=0.746, \mathrm{p}_{5}=0 . \\
006^{*}, \mathrm{p}_{6}=0.016^{*}\end{array}$} & & \\
\hline
\end{tabular}

$\mathrm{H}$ : $\mathrm{H}$ for Kruskal Wallis test, Pairwise comparison bet. Each 2 groups was done using Post Hoc Test (Dunn's for multiple comparisons test)

$\mathrm{p}$ : $\mathrm{p}$ value for comparing between the studied groups $\mathrm{p}_{1}$ : p value for comparing between Group I and Group II p2: p value for comparing between Group I and Group III p3: p value for comparing between Group I and Group IV p4: p value for comparing between Group II and Group III p5: p value for comparing between Group II and Group IV p6: p value for comparing between Group III and Group IV

*: Statistically significant at $\mathrm{p} \leq 0.05$

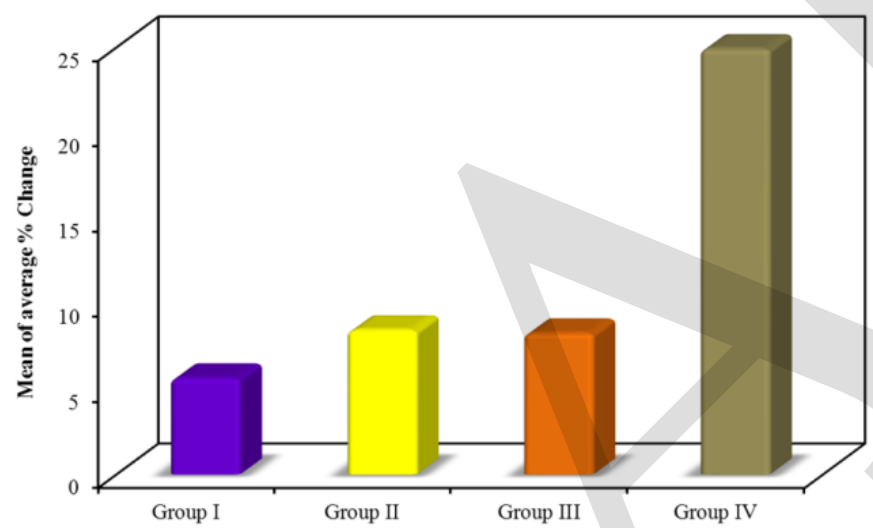

Figure (2): Graph showing Comparison between the percentage decrease values of the means of the three zones of the different studied groups.

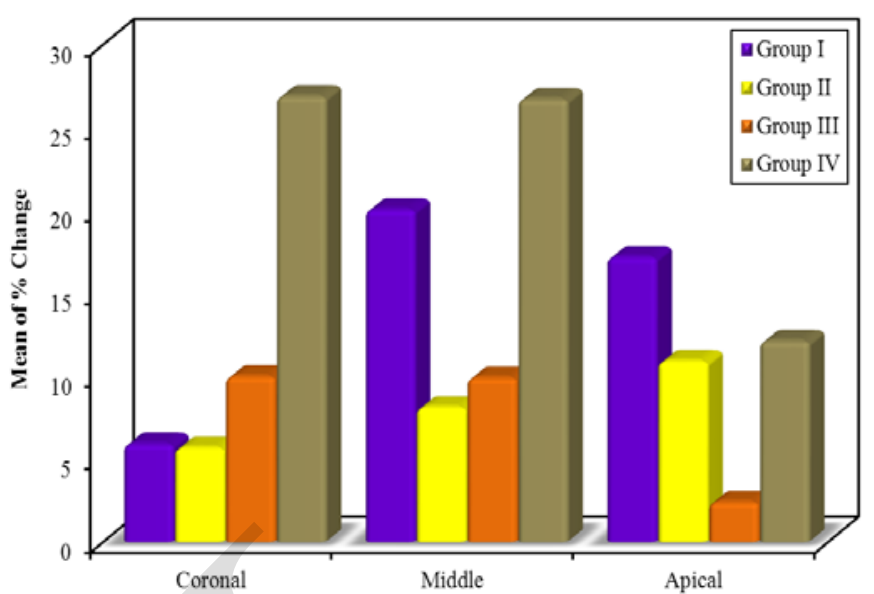

Figure (3): Graph showing comparison between different studied groups regarding the overall percentage decrease in the different root thirds.

Table (2): Comparison between different studied groups regarding the overall percentage decrease in the different root thirds.

\begin{tabular}{|c|c|c|c|c|}
\hline$\%$ decrease & $\begin{array}{c}\text { Group I } \\
\text { VHN } \\
(n=15) \\
\end{array}$ & $\begin{array}{c}\text { Group II } \\
\text { VHN } \\
(\mathbf{n}=\mathbf{1 5}) \\
\end{array}$ & $\begin{array}{c}\text { Group III } \\
\text { VHN } \\
(\mathbf{n}=15) \\
\end{array}$ & $\begin{array}{c}\text { Group IV } \\
\text { VHN } \\
(\mathrm{n}=15) \\
\end{array}$ \\
\hline $\begin{array}{l}\text { Coronal } \\
\text { Min. - } \\
\text { Max. } \\
\text { Mean } \pm \\
\text { SD. } \\
\text { Median }\end{array}$ & $\begin{array}{c}-38.42- \\
27.31 \\
5.92 \pm \\
20.43 \\
7.55\end{array}$ & $\begin{array}{c}-15.85- \\
16.29 \\
5.67 \pm 8.42 \\
6.33\end{array}$ & $\begin{array}{c}-10.63- \\
28.94 \\
9.98 \pm \\
10.41 \\
8.04\end{array}$ & $\begin{array}{c}-30.46-61.06 \\
26.88 \pm 29.21 \\
35.0\end{array}$ \\
\hline $\begin{array}{l}\text { Middle } \\
\text { Min. - } \\
\text { Max. } \\
\text { Mean } \pm \\
\text { SD. } \\
\text { Median }\end{array}$ & $\begin{array}{c}-3.26- \\
39.83 \\
20.05 \pm \\
13.26 \\
25.81\end{array}$ & $\begin{array}{c}-2.98- \\
25.93 \\
8.10 \pm 7.96 \\
8.12\end{array}$ & $\begin{array}{c}-20.71- \\
25.55 \\
9.90 \pm \\
10.72 \\
11.62\end{array}$ & $\begin{array}{c}-30.51-56.79 \\
26.71 \pm 27.73 \\
34.95\end{array}$ \\
\hline $\begin{array}{l}\text { Apical } \\
\text { Min. - } \\
\text { Max. } \\
\text { Mean } \pm \\
\text { SD. } \\
\text { Median }\end{array}$ & $\begin{array}{c}-7.19- \\
39.47 \\
17.18 \pm \\
16.55 \\
20.74\end{array}$ & $\begin{array}{c}-2.60- \\
39.40 \\
10.89 \pm \\
12.33 \\
7.54\end{array}$ & $\begin{array}{c}-16.36- \\
21.73 \\
2.40 \pm 9.43 \\
5.23\end{array}$ & $\begin{array}{c}-51.65-54.29 \\
12.12 \pm 33.83 \\
20.73\end{array}$ \\
\hline Fr & 4.133 & 1.200 & 2.533 & 0.400 \\
\hline $\mathbf{P}$ & 0.127 & 0.549 & 0.282 & 0.819 \\
\hline
\end{tabular}

Fr: Friedman test.

p: p value for comparing between the three thirds.

\section{DISCUSSION}

The use of chelating agents during biomechanical preparation of root canals removes smear layer, increasing the access of the irrigant into the dentinal tubules to allow adequate disinfection, and also reduces dentin microhardness (12). Microhardness is considered an indirect evidence of mineral changes in root canal dentin. Its reduction facilitates the instrumentation throughout the root canal but, it may also weaken the root structure, increases the permeability of root canal dentin and can affect the adhesion and sealing ability of the sealers to the root dentin wall. Therefore, finding a biocompatible agent with better chelating ability is considered 
mandatory. So this study was conducted to evaluate the effect of the chelating agents; Phytic acid (IP6) with different concentrations and ethylene diamine tetra-acetic acid (EDTA) solution on microhardness of root canal dentin.

The interaction of the chelating agents in combination with root dentin is capable of causing alteration in the physicomechanical properties of the dentin structure such as the microhardness due to change in the original proportion of the inorganic and organic components of root canal dentin (8,13-15).

Since EDTA is the universally accepted chelating agent and IP6 was proven to be an effective chelating agent (5), so these 2 chelating solutions were selected to be tested in the present study.

In the present study human teeth were used as there was a clear difference in tubule structure and morphology between human and bovine dentin as revealed by Lopes et al., (2009) (16). However other studies (17) used bovine teeth due to the inadequate availability of the human teeth. Standardization of samples is an important factor in mechanical testing to improve the reliability of the investigation $(18,19)$. Therefore, straight, single rooted teeth extracted for periodontal reasons were used to standardize the condition of the study.

There was no statistical significant difference in the mean of the pretreatment Vickers hardness values of the specimensof all the tested groups.

In the present study, canals were irrigated by using $2.5 \%$ concentration of $\mathrm{NaOCl}$ between each file as it has greater effectiveness than $0.5 \%$ and $1 \%$ concentrations and has lower cytotoxicity than the $5.25 \%$ concentration $(20,21)$.

In the current study, longitudinal sectioning of the roots was preferred instead of cutting transversally into discs as CruzFilho et al. in the year 2011 observed that it can show accurate representations of clinical situations. Additionally, the irrigants first contact the most superficial layer of dentin in the root canal lumen and so, the present study measured the microhardness of the most superficial layer of root canal dentin(3).

On the contrary, previous studies $(22,23)$ used the transverse sectioned root discs to evaluate the hardness value in the region between the main canal and the cementum layer. Surface polish of each half segment was performed following the longitudinal sectioning to facilitate the visualization of the indentations on the polished surface of the root dentin (24).

Hardness is difficult to define but in most disciplines the concept of hardness is the resistance to indentation. Hardness is measured in units of pressure or force per unit area of indentation $(12,25,26)$.

There are several types of surface hardness tests. Most are based on the ability of penetration by a diamond point or a steel ball under a specified load. Depending on the loading force value and the indentation dimensions, hardness is defined as macro-, micro- or nano-hardness $(12,25,26)$.

The term "micro-hardness" is applied to tests with a smaller test load. They are used in measuring hardness of coatings, surface hardness, or hardness of different phases in the multiphase material. There are only two micro-indentation testers: Vickers hardness test and Knoop hardness test $(9,26)$ Which are suitable and practical methods for evaluating surface changes of dental hard tissues treated with chemical agents (5). In addition, in the year 2003 Gutiérrez-Salazar and
Reyes-Gasga (27) proposed that in tooth hardness studies, the Vickers indenter is more useful than the Knoop indenter as the difference in microhardness of enamel and dentin is easily detected.In the year 2003 Fuentes et al (28) reported that the Knoop hardness tester is used only for superficial dentin at $0.1 \mathrm{~mm}$ rather than for deep dentin. Lastly, In the year 2009 Chuenarrom et al. (25) reported that the Vickers indenter is square shaped, does not deform over time while that of Knoop is shallower and more elongated. In addition, Vickers tester is based on the mean of two diagonals, compared to only one diagonal for Knoop, therefore results were more accurate by the Vickers tester. Thus, this method was adopted in our study.

In the current study, Vickers microhardness test was also used because it has shown suitability and practicability in evaluation of surface changes of dental tissues treated with chemical agents $(6,26,29)$. A load of $25 \mathrm{~g}$ for 10 seconds was applied in the present work in accordance to previous researchers (26) reported that it is necessary to apply a small load for comparison between baseline surface and the eroded surface for the same indentation as a high load applied on a soft surface can cause an oversized impression, whereas the diagonals are longer than the micrometer scale fitted to the eyepiece of the tester. It was suggested that an indentation time of 10 seconds is sufficient for a permanent indentation on the tooth surface to take place (26).

Microhardness of dentin may vary considerably between teeth, so in the present study the microhardness measurement was performed for each sample at baseline and after treatment with irrigation solutions to establish a reasonable evaluation for the effect of the irrigant solutions on the dentin surface. Posttreatment indentations were performed on each specimen at same areas that were at constant points of the baseline indentation to make evaluation of the tested irrigant (8).

Although the immersion method used in the present study did not simulate the clinical application of the irrigant solution inside the root canal which could be considered as a limitation for this study, but it was a must, as microhardness test cannot be applied on the curved plane of the root canal itself. According to previous studies the diamond indenter should be oriented perpendicular to a flat and a smooth surface of the dentin and as near as possible to the root canal space $(14,22,26,30)$

It is worthy to note that to compensate this limitation to a certain limit, the distance of the indentations in the present study were standardized at $0.2 \mathrm{~mm}$ level from the root canal walls and were made in the coronal, middle and apical thirds of the radicular dentin $(8,14)$.

Meanwhile in a previous study (31), the usual needle irrigation technique was used instead of the immersion method, a longitudinal sectioning of the root was performed then polished to measure the microhardness value but this method could be inaccurate as microhardness test cannot be applied on the curved plane of the root canal as mentioned before and they didn't measure the pretreatment base line values of their specimens.

The immersion time selected in the present study was for five minutes for each irrigating solution to simulate the clinical application time of the irrigant. This is in accordance with the studies by Sayin et al.in 2007 (10), Cruz-Filho et al. in 2011 
(3), Aslantas et al. in 2014 (32) who used the root canal irrigants for five minutes in their microhardness tests, stating that this duration is more realistic in terms of clinical practice.

In addition, De-Deus et al. in the year 2006 (33) evaluated the effect of 17\% EDTA for one, three and five minutes on the microhardness of radicular dentin. They found that EDTA produced the greatest decrease in microhardness from a reference state to three minutes and then microhardness did not change after five minutes.

On the other hand, In the year 2002 Calt and Serper (34) showed that irrigation with 17\% EDTA was time dependent; increased treatment time led to increased calcium loss and microhardness reduction. In addition, they found that one minutes EDTA irrigation is effective in removing the smear layer however; a ten minutes application of EDTA caused excessive peritubular and intertubular dentinal erosion especially when using $\mathrm{NaOCl}$ after EDTA.

Other researchers $(35,36)$ advised a longer period of irrigation for optimal results due to dentin in the apical third of the root canal is sclerosed. Hence, EDTA may not have such a pronounced action. Even more, EDTA not only removes calcium ions but also calcium bonded to non-collagenous proteins (NCPs) component of dentin. Consequently, the content of NCPs decreases in the apical third of the root canal system, led to a degree of decalcification of EDTA in this part is low (35).

In addition to contact time, the concentration of the solution needs to be considered as another determinant in the posttreatment microhardness. In the present study, $17 \%$ concentration of EDTA solution was used as it is the most common concentration in clinical practice (34). However, some studies have indicated that EDTA with a lower concentration (e.g:15, 10\%, 5\%, and even 1\%) removes the smear layer equally well after $\mathrm{NaOCl}$ irrigation and they recommended to use these lower concentrations of EDTA in clinical practice to avoid excessive erosion of root canal dentin (37)

In the present study IP6 concentrations $0.5 \%, 1 \%$ and $1.5 \%$ were used as higher concentrations with lower $\mathrm{PH}$ had an erosive effect on dentinal surface. So, it was recommended that the concentration range for IP6 should not be less than 0.5\% and not more than 3\% (5).

The present study revealed that all irrigation solutions significantly decreased dentin microhardness in the following sequence; group IV (EDTA 17\%), then group III (IP6 1.5\%), then group II (IP6 1\%) and finally group I (IP6 0.5\%).

Group IV showed the highest decrease in microhardeness in accordance to Ari and Erdemir in 2005 and De-Deus et al. in $2006(15,33)$ due to both of the chelating action of EDTA solution which induces an adverse softening potential on the calcified components of dentin $(70 \%)(6,18)$ and due to the dissolving action of $\mathrm{NaOCl}$ on the organic collagen components of dentin $(20 \%)(6,18)$.

The sequence of microhardness decrease in group III, group II and group I may be attributed to the concentrations of IP6 in each group, the higher the concentration, the higher the decrease in the microhardness value.

In the present study the tested chelators reduced the hardness at all the three levels with no significant difference between different thirds. This result is consistent with Singh et al. (38) who reported in the year 2009 that there was no significant difference in microhardness reduction in the coronal, middle, and apical thirds of root dentin when treated with the tested solutions. While other studies $(8,10)$ revealed that the coronal segments had significantly lower dentin microhardness in comparison with the middle and the apical segments. This may be attributed to the histological pattern of the root canal dentin and relative nature of dentin in the apical region as Carrigan et al. in the year 1984 (39) showed that tubule density decreased from cervical to apical dentin. In the year 1985 Pashley et al. (40) reported that there was an inverse correlation between dentin microhardness and tubular density and the ultimate tensile strength values of apical thirds were found to be significantly higher than those of coronal thirds .Previous researchers (35) reported that the apical portion of human teeth showed marked variations in structure, including accessory root canals, varied amounts of irregular secondary dentin, cementum-like tissue, low content of non-collagenous proteins (NCPs) and even dentin sclerosis.

The controversy of these results with other studies might be attributed to differences in methods of application of these irrigants and different evaluation techniques for evaluation of surface layer hardness.

A limitation of the present study is that the experiment was performed at room temperature and not at body temperature. Additionally, the volume of the irrigant in a root canal clinically is small compared with immersing root dentin in irrigating solutions. However standardized circumstances for all the studied groups were allowed for comparable results.

\section{CONCLUSIONS}

1- Within the limitations of this study, it could be concluded that significant alteration in dentin hardness after different irrigation protocols indicates potent direct effects of these chemical solutions on the components of dentin structure.

2- IP6 is a promising chelating solution which has less erosive effect on radicular dentin.

\section{CONFLICT OF INTEREST}

The authors declared that they have no conflicts of interest.

\section{REFERENCES}

1. Virdee SS, Seymour DW, Farnell D, Bhamra G, Bhakta S. Efficacy of irrigant activation techniques in removing intracanal smear layer and debris from mature permanent teeth: a systematic review and meta-analysis. Int Endod J 2018;51:605-21.

2. Calt S, Serper A. Time dependent effects of EDTA on dentine structures. J Endod 2002;28:17-9.

3. Cruz-Filho AM, Sousa-Neto MD, Savioli RN, Silva RG, Vansan LP, Pécora JD. Effect of chelating solutions on the microhardness of root canal lumen dentin. J Endod 2011;37:358-62.

4. Amaral KF, Rogero MM, Fock RA, Borelli P, Gavini G. Cytotoxicity analysis of EDTA and citric acid applied on murine resident macrophages culture. Int Endod J. 2007;40:338-43.

5. Nassar M, Hiraishi N, Tamura Y, Otsuki M, Aoki K, Tagami J. Phytic Acid: An Alternative Root Canal Chelating Agent. J Endod. 2015;41:242-7. 
6. Kandil HE, Labib AH, Alhadainy A. Effect of different irrigant solutions on microhardness and smear layer removal of root canal dentin. Tanta Dent J. 2014;1:1-11.

7. Cruz-FilhoAM, Sousa-Neto MD, Saquy PC, Pécora JD. Evaluation of the effect of EDTAC, CDTA, and EGTA on radicular dentin microhardness. J Endod. 2001;27:183-4.

8. Ulusoy Öİ, Görgül G. Effects of different irrigation solutions on root dentin microhardness, smear layer removal and erosion. Aust Endod J. 2013;39:66-72.

9. Voort GFV, Lucas GM. Microindentation Hardness Testing. Adv Mater Proc.1998;154:21-5.

10. Sayin TC, Serper A, Cehreli ZC, Otlu HG. The effect of EDTA, EGTA, EDTAC and tetracycline-HCL with and without subsequent $\mathrm{NaOCl}$ treatment on the microhardness of root canal dentin. Oral Surg Oral Med Oral Pathol Oral Radiol Endod. 2007;104:418-24.

11. Akcay I, Sen BH. The effect of surfactant addition to EDTA on microhardness of root dentin. J Endod. 2012;38:704-7.

12. Teixeira CS, Felippe MCS, Felippe WT. The effect of application time of EDTA and $\mathrm{NaOCl}$ on intracanal smear layer removal: an SEM analysis. Int Endod J. 2005;38:285-90.

13. Rotstein I, Dankner E, Goldman A, Heling I, Stabholz A, Zalkind M. Histochemical analysis of dental hard tissues following bleaching. J Endod. 1996;22:23-5.

14. Craig RG, Gehring PE, Peyton FA. Relation of structure to the microhardness of human dentin. J Dent Res. 1959;38:624-30.

15. Ari $\mathrm{H}$, Erdemir A. Effects of endodontic irrigation solutions on mineral content of root canal dentin using ICP-AES technique. J Endod. 2005;31:187-9.

16. Lopes MB, Sinhoreti MA, GoniniJúnior A, Consani S, McCabe JF. Comparative study of tubular diameter and quantity for human and bovine dentin at different depths. Braz Dent J. 2009; 20: 279-83.

17. Weshah MM. In vitro effect of $2 \%$ chlorhexidine on dentin Microhardnes. PODJ. 2011;31:173-7.

18. Ossareh A, Kishen A. Role of dentin compositional changes and structural loss on fracture predilection in endodontically treated teeth. M.Sc. Thesis. Graduate Department of Dentistry, University of Toronto. 2015. p. 1-79.

19. Baghdadi R, Hassanein I. Effect of different irrigants on same mechanical properties of dentin an attempt to improve fracture strength and microhardness of endodontically treated teeth. Egypt Dent J. 2004;50:199-208.

20. Weshah MM. In vitro effect of $2 \%$ chlorhexidine on dentin Microhardnes. PODJ. 2011;31:173-7.

21. Jefferson JC, Manhães FC, Bajo H, Duque TM. Efficiency of different concentrations of sodium hypochlorite during endodontic treatment. Dental Press Endod J. 2012;2:32-7.

22. Aranda-Garcia AJ, Kuga MC, Chavéz-Andrade GM, Kalatzis-Sousa NG, Hungaro Duarte MA, Faria G, et al. Effect of final irrigation protocols on microhardness and erosion of root canal dentin. Microsc Res Tech. 2013;76:1079-83.

23. Saghiri MA, Delvarani A, Mehrvarzfar P, Malganji G, Lotfi M, Dadresanfar B, et al. A study of the relation between erosion and microhardness of root canal dentin. Oral Surg Oral Med Oral Pathol Oral Radiol Endod.
2009;108:29-34.

24. Patil CR, Uppin V. Effect of endodontic irrigating solutions on the microhardness and roughness of root canal dentin: An in vitro study. Ind J Dent Res. 2011;22:22-7.

25. Chuenarrom C, Benjakul P, Daosodsai P. Effect of indentation load and time on Knoop and Vickers Microhardness tests for enamel and dentin. Mat Res. 2009;12:473-6.

26. Voort GFV. Hardness. In: Metallography, Principles and Practice. $4^{\text {th }}$ ed. USA: Technology \& Engineering; 2007. p. 334-82.

27. Gutiérrez-Salazar M, Reyes-Gasga J. Microhardness and chemical composition of human tooth. Mat Res. 2003;6:367-73.

28. Fuentes V, Toledano M, Osorio R, Carvalho RM. Microhardness of superficial and deep sound human dentin. J Biomed Mater Res A. 2003;66:850-3.

29. Saleh HAJ. Comparative Evaluation of Effect of Irrigation Solutions with Various Exposure Time on microhardness of Root Canal Dentin. Iraqi Dent $\mathrm{J}$. 2016;38:124-8.

30. Cirano FR, Romito GA, Todescan JH. Determination of root dentin and cementum micro hardness. Braz J Oral Sci. 2004;3:420-4.

31. Al-Ashou WM. The Effects of Two Root Canal Irrigants and Different Instruments on Dentin Microhardness (In Vitro Study). Al-Rafidain Dent J. 2011;11:63-70.

32. Aslantas EE, Buzoglu HD, Altundasar E, Serper A. Effect of EDTA, sodium Hypochlorite, and chlorhexidinegluconate with or without surface modifiers on dentin microhardness. J Endod. 2014;40:876-97.

33. De-Deus G, Paciornik S, Mauricio MH. Evaluation of the effect of EDTA, EDTAC, and Citric acid on the microhardness of root dentin. Int Endod J. 2006;39:401-7.

34. Çalt S, Serper A. Time-dependent effects of EDTA on dentin structures. Endod J. 2002;28:17-9.

35. Paque F, Luder HU, Sener B, Zehnder M. Tubular sclerosis rather than the smear layer impededs dye penetration in to the dentin of endodontically instrumented root canals. Int Endod J. 2006;39:18-25.

36. Torabinejad M. Root Canal Irrigants and Disinfectants. Chicago, IL: American Association of Endodontists Colleagues for Excellence, Newsletter; 2011. p.1-7.

37. Haapasalo $M$, Shen $Y$, Qian W, Gao Y. Irrigation in endodontics. Dent Clin North Am. 2010;54:291-312.

38. Singh S, Acharya SR, Ballal V, Rijesh M. Evaluation of the effect of EDTA, EDTAC, RC-Prep and BioPure MTAD on the microhardness of root canal dentin -An in vitro study. Endodont. 2009;21:35-41.

39. Carrigan PL, Morse DR, Furst ML, Sinai IH. A scanning electron microscopic evaluation of human dentinal tubules according to age and location. J Endod. 1984;10:359-63.

40. Pashley D, Okabe A, Parham P. The relationship between dentin microhardness and tubule density. Endod Dent Traumatol. 1985;1:176-9. 